\title{
Heat shock protein $90 \beta$ in the Vero cell membrane binds Japanese encephalitis virus
}

\author{
YUAN WANG ${ }^{1}$, YAN LI $^{1,2}$ and TIANBING DING ${ }^{1}$ \\ ${ }^{1}$ Department of Microbiology, The Fourth Military Medical University, Xi'an, Shaanxi 710032; \\ ${ }^{2}$ Department of Clinical Laboratory, Shandong Provincial Qianfoshan Hospital, Jinan, Shangdong 250014, P.R. China
}

Received May 10, 2016; Accepted June 14, 2017

DOI: $10.3892 /$ ijmm.2017.3041

\begin{abstract}
The pathogenesis of Japanese encephalitis virus (JEV) is complex and unclearly defined, and in particular, the effects of the JEV receptor (JEVR) on diverse susceptible cells are elusive. In contrast to previous studies investigating JEVR in rodent or mosquito cells, in this study, we used primate Vero cells instead. We noted that few novel proteins co-immunoprecipitated with JEV, and discovered that one of these was heat shock protein $90 \beta$ (HSP90 $\beta$ ), which was probed by mass spectrometry with the highest score of 60.3 after questing the monkey and human protein databases. The specific HSP90 $\beta$-JEV binding was confirmed by western blot analysis under non-reducing conditions, and this was significantly inhibited by an anti-human HSP90 $\beta$ monoclonal antibody in a dose-dependent manner, as shown by immunofluorescence assay and flow cytometry. In addition, the results of confocal laser scanning microscopic examination demonstrated that the HSP90 $\beta$-JEV binding occurred on the Vero cell surface. Finally, JEV progeny yields determined by plaque assay were also markedly decreased in siRNA-treated Vero cells, particularly at 24 and $36 \mathrm{~h}$ post-infection. Thus, our data indicate that HSP90 $\beta$ is a binding receptor for JEV in Vero cells.
\end{abstract}

\section{Introduction}

Japanese encephalitis (JE) is an acute and severe viral infection of the human central nervous system that is caused by $\mathrm{JE}$ virus (JEV) and is transmitted between animal hosts and humans by mosquitoes (mostly of the genus Culex) (1). It is prevalent throughout Eastern and South Eastern Asia and has expanded onto the Cape York Peninsula of Northern Australia (2-4); it has affected approximately 60\% of the global population in endemic countries at risk of exposure to

Correspondence to: Dr Tianbing Ding, Department of Microbiology, The Fourth Military Medical University, 169 Changle West Road, Xi'an, Shaanxi 710032, P.R. China

E-mail: dingtb@fmmu.edu.cn

Key words: Japanese encephalitis virus, Vero cell, membrane protein, heat shock protein $90 \beta$, binding
JEV. JE primarily occurs in children under 15 years of age and the elderly when protective immunity decreases $(2,5)$. Fortunately, most JEV infections are subclinical with a symptomatic-to-asymptomatic ratio of 1:25-1,000 (6,7). With thebroad administration of inactivated and attenuated live vaccines, the annual JE incidence is estimated to range from $50,000-175,000$ cases. Approximately $20-30 \%$ of cases are fatal, and approximately $30-50 \%$ of survivors suffer serious neurologic, cognitive, or psychiatric complications several years thereafter (8-10). Therefore, JE remains a significant health threat to the public worldwide.

The JEcausal agent, JEV, is a member of the genus Flavivirus, of the family Flaviviridae. The virion is spherical, small in size $(40-60 \mathrm{~nm})$ and contains an electron dense core $\sim 30 \mathrm{~nm}$ in diameter that is surrounded by a lipid bilayer envelope. The viral genome is composed of a positive-sense, 10,976-nucleotide, single-stranded RNA, which features a methylated cap at the $5^{\prime}$ end and does not contain a $3^{\prime}$ poly (A) tail (11). Flanked by hundreds of nucleotides in non-coding regions (NCRs) on both termini, the viral RNA encodes a single long open reading frame $(\mathrm{ORF})$ and translates into a large polyprotein precursor that is subsequently processed into structural (C, M and $\mathrm{E})$ and non-structural (NS1, NS2A, NS2B, NS3, NS4A, NS4B and NS5) proteins by cellular and viral proteinases (12).

In viral encoded proteins, the envelope $\mathrm{E}$ protein on the virion surface is the most crucial protein involved in virus-host interactions, particularly during attachment to the cell receptor, virus penetration, cell tropism and virulence, as well as haemagglutination and neutralization in human protective immunity (13). The E protein consists of 500 amino acid residues, appears as approximately $53 \mathrm{kDa}$, and is $\mathrm{N}$-glycosylated (14). An exact crystal structure of the JEV E protein ectodomain (1-406) was previously produced and the major conformational properties previously suggested were confirmed based on a related flavivirus [tick borne encephalitis virus (TBEV)] E protein counterpart $(15,16)$. In brief, the $E$ protein is present on the virion surface as an anti-parallel homodimer with a convex external curvature and is anchored to the viral envelope (lipid membrane) at the distal end. Each E protein subunit is composed of 3 domains based on antigenicity (13). Domain I is a discontinuous domain composed of 3 fragments (1-51, 137-189 and 293-311 amino acids from the amino terminal end) and is the central domain with an 8 -stranded $\beta$-barrel located in the centre of the E protein molecule. Domain II is the 
dimerization domain on the mature virion, forms 2 loops from regions 52-136 and 190-289, projects along the virus surface between the homodimer subunit transmembrane regions, and contains a highly conserved fusion loop that likely inserts into target cell membranes (17). Domain III (311-411) lies at the E protein C-terminus, forms a constant $\beta$-barrel composed of 7 head-to-tail $\beta$-strands, and maintains an immunoglobulin-like fold (18). It contains the receptor-binding domain, which is connected to the central domain I by a flexible region and is a major target of neutralizing antibodies (19).

To inititiate JEV pathogenesis, the JEV E protein and the cellular receptor on the surface of susceptible cells form an initial interaction (20-24). Therefore, determining the cellular receptor is a prerequisite for future investigations into precise molecular events involved in JEV binding and entry into cells, which has always been an intriguing basic virology field. Research has advanced over the past few decades. Early in 1994, researchers discovered that a $74 \mathrm{kDa}$ molecule from Vero (African green monkey kidney) cells can bind JEV without further characterization (20). Later, researchers found that a $57 \mathrm{kDa}$ protein from BHK-21 (baby hamster kidney) cells (21) and a GAG protein in Chinese hamster ovary (CHO) cells (22) may be involved in JEV attachment or entry. In previous studies from our laboratory, we generated several pieces of evidence and, thus, hypothesised that heat shock cognate protein 70 (HSC70) may act as a JEV binding receptor on mosquito $\mathrm{C} 6 / 36$ cells (23). It has been reported that heat shock protein (HSP)70, which is present in the membrane fraction from mouse neuroblastoma cells (Neuro2a), is the putative receptor for JEV (24). In addition, using a mouse microglial cell line, researchers have demonstrated that the extracellular matrix protein, laminin, and several other candidate receptor molecules, including HSP70, HSP90, GRP78, CD14 and CD4, are involved in JEV entry (25). Nevertheless, these studies are limited to rodent or mosquito cells, and the interacting cellular proteins from human or at least primate cells are necessary to elucidate the functional role of $\mathrm{E}$ protein with interacting cellular proteins. Herein, we discovered that HSP90 $\beta$ in the monkey cell (Vero) membrane binds JEV particles.

\section{Materials and methods}

JEV propagation, purification and titration. The JEV strain SA14 (isolated in Xi'an, China in the 1950's, and stored in a refrigerator in our laboratory ever since) was propagated in C6/36 cells (ATCC ${ }^{\circledR}$ CRL-1660 ${ }^{\mathrm{TM}}$; Institute for Microbial Epidemiology, Academy of Military Medical Sciences, Beijing, China) cultured at $28^{\circ} \mathrm{C}$ in a closed incubator in RPMI-1640 medium (Invitrogen Life Technologies, Carlsbad, CA, USA) containing $10 \%$ foetal calf serum (FCS; HyClone Laboratories Inc., Logan, UT, USA), $1 \%$ lactoalbumin hydrolysate (LH) and antibiotics (penicillin and streptomycin). When CPE was apparent, the culture supernatants were harvested following centrifugation at $500 \times \mathrm{g}$ at $4^{\circ} \mathrm{C}$ for $10 \mathrm{~min}$. The supernatants were then received a serial centrifugation in $10,000 \mathrm{x} \mathrm{g}$ for $20 \mathrm{~min}, 45,000 \mathrm{x} \mathrm{g}$ for $10 \mathrm{~min}$ and 70,000 x g for $4 \mathrm{~h}$ at $4^{\circ} \mathrm{C}$ (Optima L-100XP Ultracentrifuge, Beckman Coulter, Brea, CA, USA). Viral particles were condensed in aliquots and preserved at $-80^{\circ} \mathrm{C}$ for use in subsequent experiments.

The condensed JEV was titrated by plaque formation assay with a semi-solid overlay. BHK-21 cells (ATCC ${ }^{\circledR}$ CCL-10 ${ }^{\mathrm{TM}}$ ) were obtained from Ms. L. Jia (The National Institute for the Control of Pharmaceutical and Biological Products, Beijing, China). BHK-21 cells were used in JEV titration and JEV progeny determination in RNAi-treated Vero cells, while attempt to identify molecules capable of binding JEV by VOPBA using BHK-21 cells failed (unpublished data). Briefly, BHK-21 cells $\left(1 \times 10^{5}\right.$ cells/well $)$ were grown to a confluent monolayer in a 6 -well plate in culture medium [containing $60 \%$ RPMI-1640, 30\% 0.5\% LH, 10\% FCS, $1 \%$ penicillin, $100 \mathrm{IU} / \mathrm{ml}$ streptomycin, $0.75 \% \mathrm{NaHCO}_{3}$ (1\% in total) $\mathrm{NaHCO}_{3}$ and $3 \%$ glutamine (1\% in total)] and infected with $200 \mu \mathrm{l}$ of 10 -fold serially diluted JEV aliquots dissolved in virus dilution solution [containing $96 \% \mathrm{LH}, 2 \% \mathrm{FCS}$, and $0.75 \% \mathrm{NaHCO}_{3}(2 \%$ in total)]. The cells absorbed the virus at $37^{\circ} \mathrm{C}$ for $1 \mathrm{~h}$ with gentle circular tilting every $15 \mathrm{~min}$. The fluids were then pipetted out, and the monolayers were washed 3 times with RPMI-1640 without serum and finally covered with a semi-solid overlay [containing 1\% methyl cellulose, 1/10 volume 10X RPMI-1640, $25 \%$ distilled water, $10 \%$ FCS, $1 \%$ antibiotics (penicillin and streptomycin), $0.75 \% \mathrm{NaHCO}_{3}(3 \%$ in total) and $3 \%$ glutamine (1\% in total)]. Following incubation at $37^{\circ} \mathrm{C}$ for $96 \mathrm{~h}$, the overlay was withdrawn, and the cell monolayer was stained with a $1 \%$ crystal violet solution containing $0.2 \%$ formaldehyde. All plaque formation assay experiments were performed in triplicate, and the plaques were counted and calculated in PFU/ml.

Cell membrane protein extraction. Vero cells (ATCC ${ }^{\circledR}$ CCL-81 ${ }^{\mathrm{TM}}$ ) were obtained from Ms. L. Jia (The National Institute for the Control of Pharmaceutical and Biological Products). Vero cell membrane proteins were prepared as previously described (26) with minor modifications. Briefly, the cells were cultured in RPMI-1640 medium containing $10 \%$ FCS in an incubator (Hera Cell; Heraeus Holding GmbH, Hanau, Germany) with $5 \% \mathrm{CO}_{2}$ at $37^{\circ} \mathrm{C}$. Confluent cell monolayers were washed 3 times with PBS, treated with $1 \mathrm{mM}$ EDTA in PBS (pH 7.2) for $3 \mathrm{~min}$ at $37^{\circ} \mathrm{C}$, and subsequently resuspended in ice cold Buffer $\mathrm{M}(100 \mathrm{mM} \mathrm{NaCl}, 20 \mathrm{mM}$ Tris- $\mathrm{HCl} \mathrm{pH} 8.0,2 \mathrm{mM} \mathrm{MgCl}{ }_{2}, 1 \mathrm{mM}$ EDTA and $1 \mathrm{mM}$ $\beta$-mercaptoethanol) containing $1 \mathrm{mM}$ phenylmethanesulfonyl fluoride (PMSF; Sigma-Aldrich, St. Louis, MO, USA) on ice for 40 min with intermittent shaking, and lysed using 15-20 strokes and a Dounce homogeniser. The nuclei and cell debris were removed by centrifugation at $500 \mathrm{xg}$ and $4^{\circ} \mathrm{C}$ for $10 \mathrm{~min}$. The membrane-bound proteins in the supernatant fraction were condensed through further centrifugation at 36,000 $\mathrm{x} \mathrm{g}$ and $4^{\circ} \mathrm{C}$ for $30 \mathrm{~min}$. The pellet was dissolved in Buffer $\mathrm{M}$ without $\beta$-mercaptoethanol. The concentrations of the membrane proteins were determined using a BCA kit (Pierce; Thermo Fisher Scientific Inc., Rockford, IL, USA).

Co-immunoprecipitation (Co-IP) and SDS-PAGE. We thoroughly mixed $160 \mu \mathrm{g}$ membrane protein extracts with purified JEV $\left(5 \times 10^{6} \mathrm{PFU} / \mathrm{ml}\right)$ in $1 \mathrm{ml}$ microcentrifuge tubes on ice and added an equal volume of $2 \mathrm{X}$ IP buffer $(150 \mathrm{mM}$ $\mathrm{NaCl}, 50 \mathrm{mM}$ Tris-HCl, $5 \mathrm{mM}$ EDTA, $\mathrm{pH}$ 8.0) containing $1 \% \mathrm{NP}-40$ overnight at $4^{\circ} \mathrm{C}$. The complex was incubated with mouse anti-JEV monoclonal antibody (mAb) $2 \mathrm{H} 4$ (created and produced in our laboratory) (27) overnight at $4^{\circ} \mathrm{C}$ and separated through reacting with protein $\mathrm{A} / \mathrm{G}$ agarose beads (Santa Cruz Biotechnology, Inc., Dallas, TX, USA) for $2 \mathrm{~h}$ at $4^{\circ} \mathrm{C}$ in a rocker 
on the lowest setting. The beads were washed 3 times with 1X IP buffer and centrifuged at 3,000 $\mathrm{x} \mathrm{g}$ for $5 \mathrm{~min}$ at $4^{\circ} \mathrm{C}$, and the pellets with bound proteins were analysed through $10 \%$ SDS-PAGE after boiling for $5 \mathrm{~min}$. The protein bands in the gels were stained by Coomassie brilliant blue (Amresco, Solon, OH, USA).

Mass spectrometry (MS) analysis. Novel stained bands of the Co-IP immunocomplex on SDS-PAGE gels were excised for matrix-assisted laser desorption ionization-time of flight MS (MALDI-TOF MS). Briefly, a gel with a single band was minced into sections at approximately $1 \mathrm{~mm}^{3}$ and transferred into a sterile microcentrifuge tube. The gel sections were immersed in a $500 \mu \mathrm{l}$ preservation solution (50\% acetonitrile, $50 \%$ distilled water) and mailed to the laboratory in Beijing (see Acknowledgements) at room temperature for further MS processing protocol and analysis. Protein identity was determined based on a score of $>30$ from the homology search tool MASCOT, where the mass/charge values matched the information available in primate databases (28).

Western blot analysis for HSP90 $\beta$-JEV binding. We routinely used western blot analysis to detect JEV binding with HSP90 $\beta$ from the Vero membrane protein extracts under non-reducing and non-boiling conditions. Due to the unavailability of anti-monkey HSP90 $\beta$ antibodies and the high homogeneity of HSP90 $\beta$ between humans and monkeys, a rabbit anti-human HSP90 $\beta$ mAb (Product no. ab32568; Abcam, Cambridge, UK) was used for blotting (1:500 in TBS containing 5\% powdered milk). We then used Odyssey ${ }^{\mathrm{TM}}$ IRDye680-labelled goat anti-rabbit IgG (1:5,000; Cat. no. 926-68071; LI-COR Biosciences, Lincoln, NE, USA). In a parallel blotting test, rabbit anti-human HSP90 $\beta$ mAb was replaced by purified JEV $\left(1 \times 10^{9} \mathrm{PFU} / \mathrm{ml}\right)$ followed by the addition of anti-JEV $\mathrm{mAb} 2 \mathrm{H} 4(22 \mu \mathrm{g} / \mathrm{ml})$ and Odyssey ${ }^{\mathrm{TM}}$ IRDye680-labelled goat anti-mouse IgG (1:5,000; Cat. no. 926-68070; LI-COR Biosciences). The results were scanned and analysed by GelDoc-It $^{\mathrm{TM}}$ (Ultra-Violet Products Ltd., Cambridge, UK).

Confocal laser scanning microscopy (CLSM). Routine CLSM was performed (29) to detect the location of HSP90 $\beta$-JEV binding. Briefly, Vero cells were prepared on glass coverslips, fixed by paraformaldehyde, and incubated with JEV $\left(1.2 \times 10^{5} \mathrm{PFU} / \mathrm{ml}\right)$ at $37^{\circ} \mathrm{C}$ for $1 \mathrm{~h}$. After washing 3 times with PBS, a primary antibody (1:10 anti-JEV mAb $2 \mathrm{H} 4$, and 1:50 rabbit anti-human HSP90 $\beta$ mAb, respectively) was added followed by incubation overnight at $4^{\circ} \mathrm{C}$, and the secondary antibody [1:100 FITC-conjugated goat anti-mouse IgG (Sigma-Aldrich $^{\mathrm{TM}}$ Cat. no. F9006), and 1:100 Cy3-conjugated goat anti-rabbit IgG (Sigma-Aldrich ${ }^{\mathrm{TM}}$ Cat. no. C2306), respectively (Sigma-Aldrich)] was added followed by incubation in the dark at room temperature for $1 \mathrm{~h}$ followed by a PBS wash 3 times. The coverslips were then thoroughly rinsed in deionised water, air dried, placed reversely on a glass slide mounted with mixture of $50 \%$ glycerol and an equal volume Hoechst (1:1,000; Beyotime Institute of Biotechnology, Shanghai, China), and the samples were finally observed under an Olympus FV-1000 microscope with the image analysis software package FV1000 Viewer v1.4a (Olympus Corp; Tokyo, Japan).
Immunofluorescence assay (IFA). When HSP90 $\beta-J E V$ binding on the Vero cell surface was confirmed, a JEV infection inhibition test was performed under impermeable conditions using an IFA with the rabbit anti-human HSP90 $\beta$ mAb mentioned above. Well-grown Vero cells were treated with 3.5 mM EDTA instead of trypsin to avoid cell surface protein digestion, washed with PBS, and transferred onto glass coverslips $\left(15 \mu \mathrm{l}, 1 \times 10^{6} / \mathrm{ml}\right)$ in 24-well plates and grown with 10\% FCS RPMI-1640 in a humidified incubator with $5 \% \mathrm{CO}_{2}$ at $37^{\circ} \mathrm{C}$. When the confluence reached 50-60\%, the cells were washed 3 times with PBS and were fixed in 4\% PBS-buffered formaldehyde for $30 \mathrm{~min}$ at room temperature. After a PBS wash, the fixed cells were successively incubated with rabbit anti-human HSP90 $\beta \mathrm{mAb}$ (two concentrations of $10 \mu \mathrm{g} / \mathrm{ml}$ and $20 \mu \mathrm{g} / \mathrm{ml}$ ) at $4^{\circ} \mathrm{C}$ for $2 \mathrm{~h}$, titrated JEV $(\mathrm{MOI}=0.1)$ at $4^{\circ} \mathrm{C}$ overnight, anti-JEV mAb $2 \mathrm{H} 4$ (1:10, primary antibody) at $4^{\circ} \mathrm{C}$ for $2 \mathrm{~h}$ and FITC-conjugated goat anti-mouse IgG (1:100, secondary antibody; Bioworld Technology, Inc., St. Louis Park, MN, USA) at room temperature for $1 \mathrm{~h}$. Immunofluorescence was observed under a BH-60 immunofluorescence microscope (Olympus Corp.) after glycerol mounting.

Flow cytometry (FCM). FCM was performed using a routine procedure. Briefly, the Vero cells were treated with PBS containing 3.5 mM EDTA, washed 3 times with FCM dilution, and resuspended (adjusting concentration to $1 \times 10^{6} / \mathrm{ml}$ ). Vero cells (50 $\mu \mathrm{l}$ per tube) were consecutively incubated with rabbit anti-human HSP90 $\beta$ mAb (1:100 and 1:50), JEV (MOI=1), anti-JEV mAb 2H4 (1:10) and FITC-conjugated goat anti-mouse $\operatorname{IgG}(1: 100)$ at $4^{\circ} \mathrm{C}$ for $1 \mathrm{~h}$ with gentle shaking. Each incubation step was interspersed by washing 3 times with an FCM dilution solution and centrifugation at 1,000 rpm and $4^{\circ} \mathrm{C}$ for $5 \mathrm{~min}$. Finally, the cells were fixed in $300 \mu \mathrm{l}$ $4 \%$ PBS-buffered formaldehyde, and immunofluorescence was detected using a flow cytometer (Epics Elite ESP; Beckman Coulter Inc., Indianapolis, IN, USA). All detection experiments were performed in quadruplicate.

Suppression of HSP90 $\beta$ expression in Vero cells through siRNA. Several siRNA fragments were synthesised based on the human HSP $90 \beta$ mRNA transcript sequence from the NCBI PDB database. Following the general principles of siRNA design (30), several siRNA fragments were synthesised, subcloned into lentiviral vectors (Cat. no. HPK-LvTR-20; GeneCopoeia, Rockville, MD, USA), packaged in the 293Ta lentiviral packaging cell line (Cat. no. Clv-PK-01; GeneCopoeia), and the pseudoviruses thus produced infected intact Vero cells in the presence of $5 \mu \mathrm{g} / \mathrm{ml}$ hexadimethrine bromide. We considered HSP90 $\beta$ expression inhibition over $50 \%$ effective as void of off-target effects, and the fragment was selected for further experiments. Cells with reduced HSP90 $\beta$ expression were then subjected to JEV infection (MOI=0.1), and progeny virus yields were measured using plaque formation assay at 12, 24, 36 and 48 hours post-infection (hpi).

Statistical analysis. The quantitative measurement results are expressed as the means \pm standard deviation. One-way ANOVA t-test was used to determine statistical differences between the means: a value of $\mathrm{P}<0.05$ was considered to indicate a statistically significant difference. These t-tests were 
Table I. Results of mass spectrometry analysis of the novel bands.

A, Monkey (Macaca fascicularis) protein database

\begin{tabular}{|c|c|c|c|c|}
\hline Serial no. & Reference & Score & Accession & Peptides (hits) \\
\hline 1 & Unnamed protein product & 80.5 & 67971184.0 & $8(80,000)$ \\
\hline 2 & Unnamed protein product & 40.4 & 67971096.0 & $4(40,000)$ \\
\hline
\end{tabular}

B, Human (Homo sapiens) protein database

\begin{tabular}{|c|c|c|c|c|}
\hline Serial no. & Reference & Score & Accession & Peptides (hits) \\
\hline 1 & Heat shock protein $90 \mathrm{kDa} 1, \beta$ & 60.3 & 20149594.0 & $6(60,000)$ \\
\hline 2 & Unnamed protein product $\mathrm{A}$ & 60.2 & 32486.0 & $6(60,000)$ \\
\hline 3 & $\begin{array}{l}\text { chain } \mathrm{A} \text {, the } 3 \text {-dementional structure } \\
\text { of glutathione } \mathrm{S} \text {-transferase }\end{array}$ & 30.2 & 157831214.0 & $3(30,000)$ \\
\hline 4 & Aconitase 2 precursor & 30.2 & 4501867.0 & $3(30,000)$ \\
\hline
\end{tabular}

The serial numbers listed in this table are not one-to-one matched with gel bands indicated by arrows in Fig. 1 .

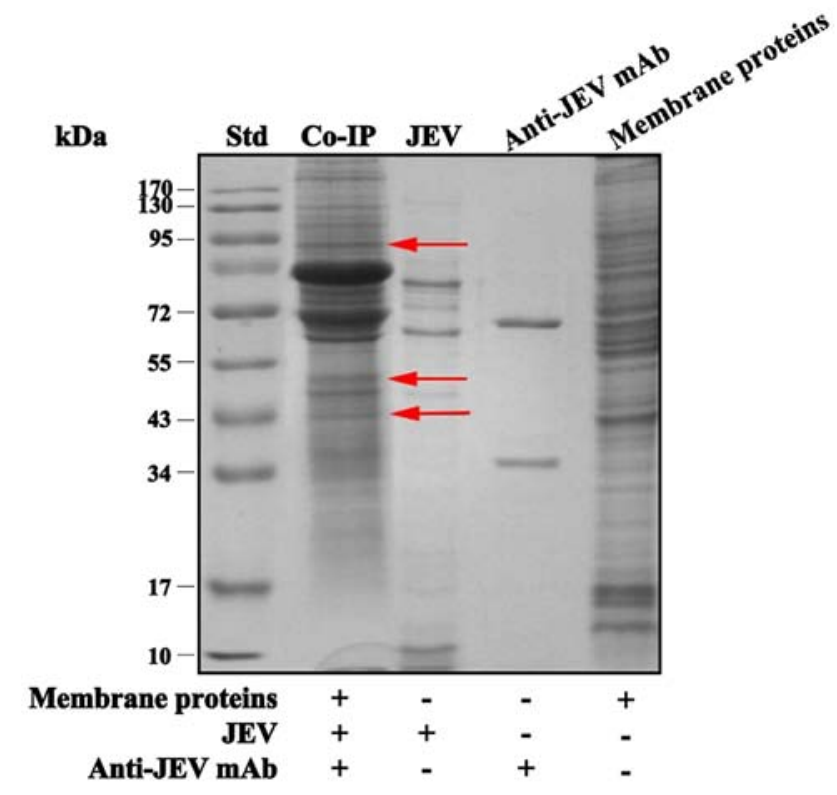

Figure 1. A representative SDS-PAGE analysis result of the Co-IP experiments. Vero membrane protein extracts were precipitated with JEV and anti-JEV $\mathrm{mAb} 2 \mathrm{H} 4$, and subjected to SDS-PAGE under non-reducing conditions. Three novel bands at approximately 43,55 and $95 \mathrm{kDa}$ (indicated by red arrows) in the Co-IP lane were noticed, and the gels were excised for mass spectrometry analyses. Co-IP, Co-Immunoprecipitation; mAb, monoclonal antibody; JEV, Japanese encephalitis virus.

performed using Prism 5.0 software (GraphPad Software Inc., La Jolla, CA, USA).

\section{Results}

Results of Co-IP and MS analyses. The immunocomplexes, formed by membrane proteins, JEV and anti-JEV $\mathrm{mAb}$, were precipitated, washed, centrifuged and subjected to SDS-PAGE (Fig. 1). The results ostensibly indicated 3 novel protein bands at approximately 43, 55 and $95 \mathrm{kDa}$, present in the membrane protein sample but not present in the JEV and anti-JEV mAb controls. These gel bands were cut off in sections for further MS analyses.

In MS experiments, the peptide sequences from the gels were quested in the monkey database but generated no matches, as the African green monkey (Cercopithecus aethiops) database is not available. Therefore, the human database (Homo sapiens) had to be used instead, and the 95-kDa-molecule was probed as HSP90 $\beta$, with a moderate score of 60.3 (Table I), and then selected as an entire functioning protein for further investigation.

HSP90 $\beta$ from the Vero membrane binds JEV on the Vero cell surface. First, western blot analysis was used to test the binding between JEV and HSP90 $\beta$ in the Vero membrane. Following non-reducing SDS-PAGE, Vero membrane protein extract samples were transferred onto PVDF membranes and reacted with rabbit anti-human HSP90 $\beta$ mAb (as anti-monkey HSP90 $\beta$ mAbs are unavailable) and indicated by fluorescent goat anti-rabbit IgG (Fig. 2A, lane 1). Vero membrane protein samples also reacted alone with JEV and anti-JEV mAb $2 \mathrm{H} 4$ (Fig. 2A, lane 2) at the same $90 \mathrm{kDa}$ position, indicating that HSP90 $\beta$ binds JEV. Later, confocal laser scanning microscopy was performed. As shown in Fig. 2B, JEV (green colour, Fig. 2B, panel 2) and HSP90 $\beta$ (red colour, Fig. 2B, panel 3) merger displayed yellow fluorescence on the cell surface (Fig. 2B, panel 4), evidently suggesting that the presence of HSP90 $\beta$ in the cell membrane binds JEV exactly on the cell surface.

Specific $m A b$ inhibits HSP90 $\beta$-JEV binding in a dose-dependent manner. When the binding of HSP90 $\beta$ and JEV was ascertained, a virus infection inhibition experiment with rabbit anti-human HSP90 $\beta$ mAb at various concentrations was conducted using qualitative IFA and quantitative FCM. In the IFA experiment, green fluorescence gradually decreased with an increase in the anti-HSP90 $\beta$ mAb concentrations 0,10 and $20 \mu \mathrm{g} / \mathrm{ml}$ (Fig. 3A). 

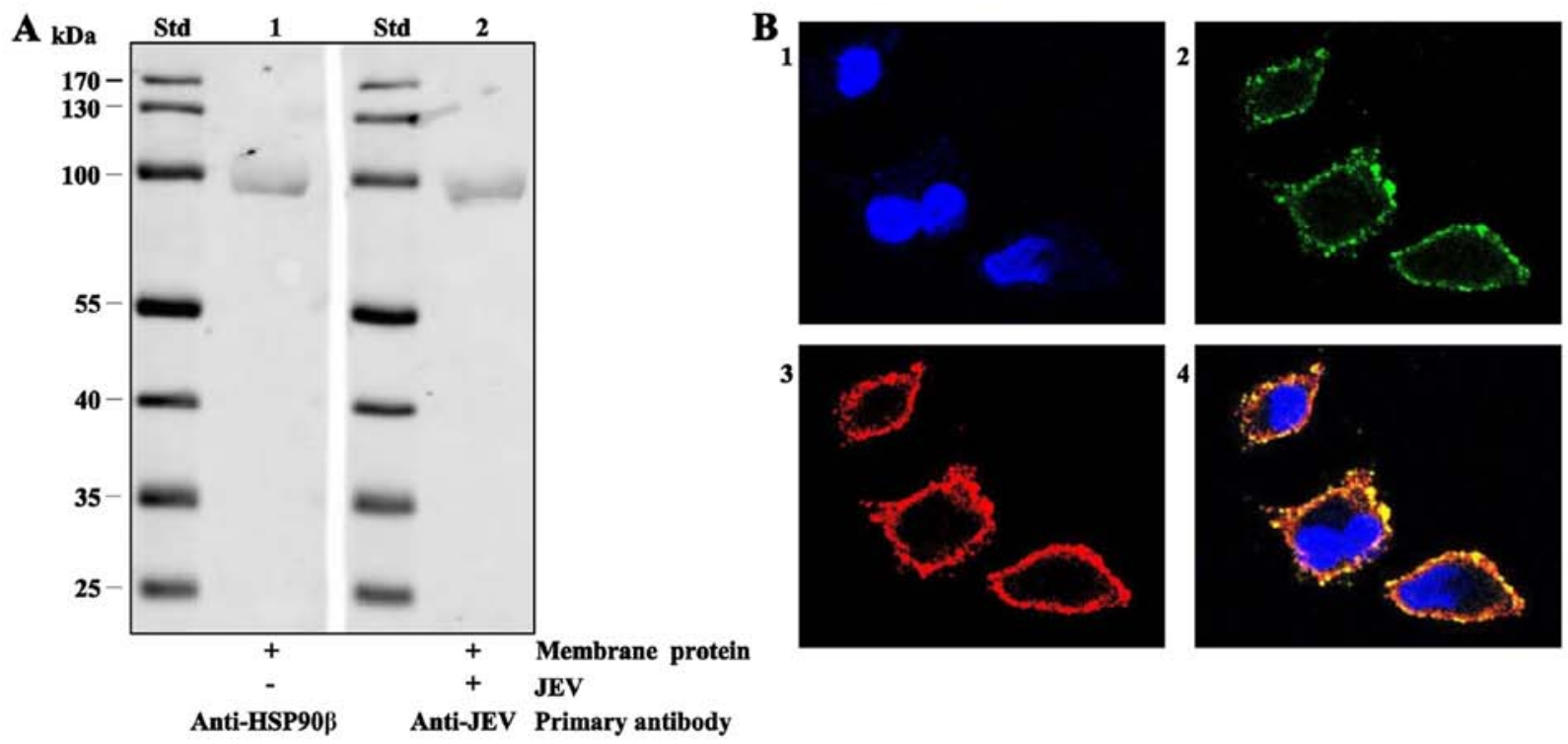

Figure 2. HSP90 $3-J E V$ binding detected by western blot analysis and confocal laser scanning microscopic examination (magnification, x600). (A) Western blot analysis results. A membrane protein component both reacted solely with rabbit anti-human HSP90 $\beta$ (lane 1) mAb and JEV (lane 2) at the same molecular weight position, approximately $90 \mathrm{kDa}$. (B) Confocal laser scanning microscopic results. JEV (in green colour, panel 2) and HSP90 $\beta$ (in red colour, panel 3) produced yellow colour (panel 4) after merging JEV and HSP90ß. JEV, Japanese encephalitis virus; mAb, monoclonal antibody.

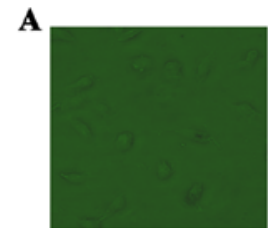

Negative control

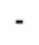

$-$

$+$

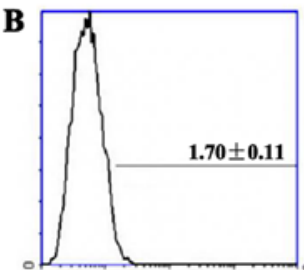

Negative control

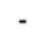

$-$

$+$

C

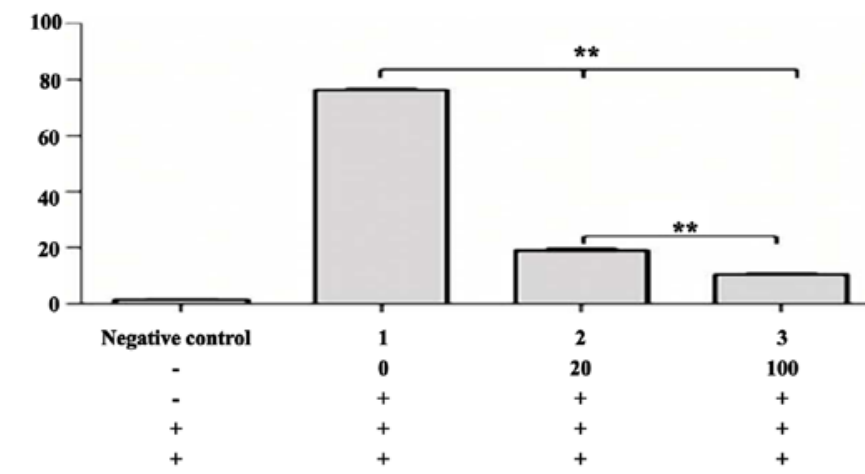

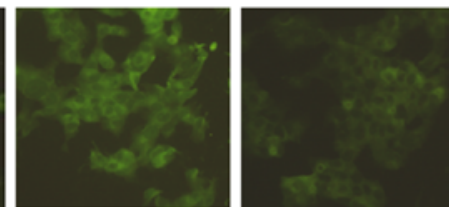

2

10

$+$

$+$

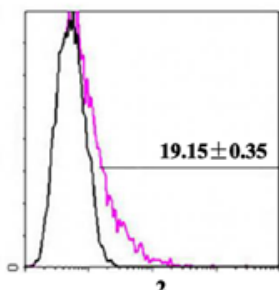

20

$+$

$+$

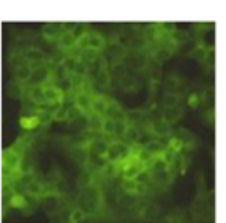

Positive control

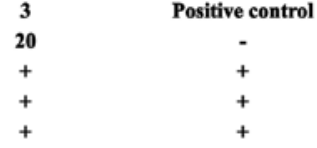

Anti-HSP90ß mAb $(\mu \mathrm{g} / \mathrm{ml})$

JEV

Anti-JEV mAb

FITC-labeled secondary antibody

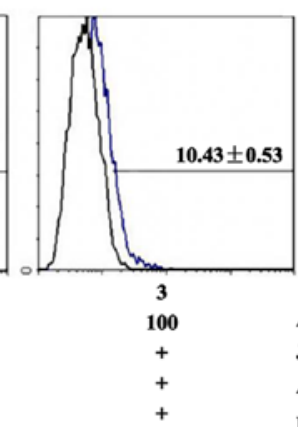

Anti-HSP90ß mAb $(\mu \mathrm{g} / \mathrm{ml})$

JEV

Anti-JEV mAb

FITC-labeled secondary antibody

Figure 3. Specific anti-human HSP90 $\beta$ mAb inhibited HSP90 $\beta$-JEV binding on the cell surface in a dose-dependent manner. (A) HSP90 $\beta$-JEV binding was exhibited using IFA (magnification, x400). (B) Histograms of FCM detection at various concentrations of the anti-human HSP90 $\beta$ mAb. (C) HSP90 $\beta$-JEV binding percentages measured by $\mathrm{FCM}^{* *} \mathrm{P}<0.01$. mAb, monoclonal antibody; JEV, Japanese encephalitis virus; FCM, flow cytometry. 

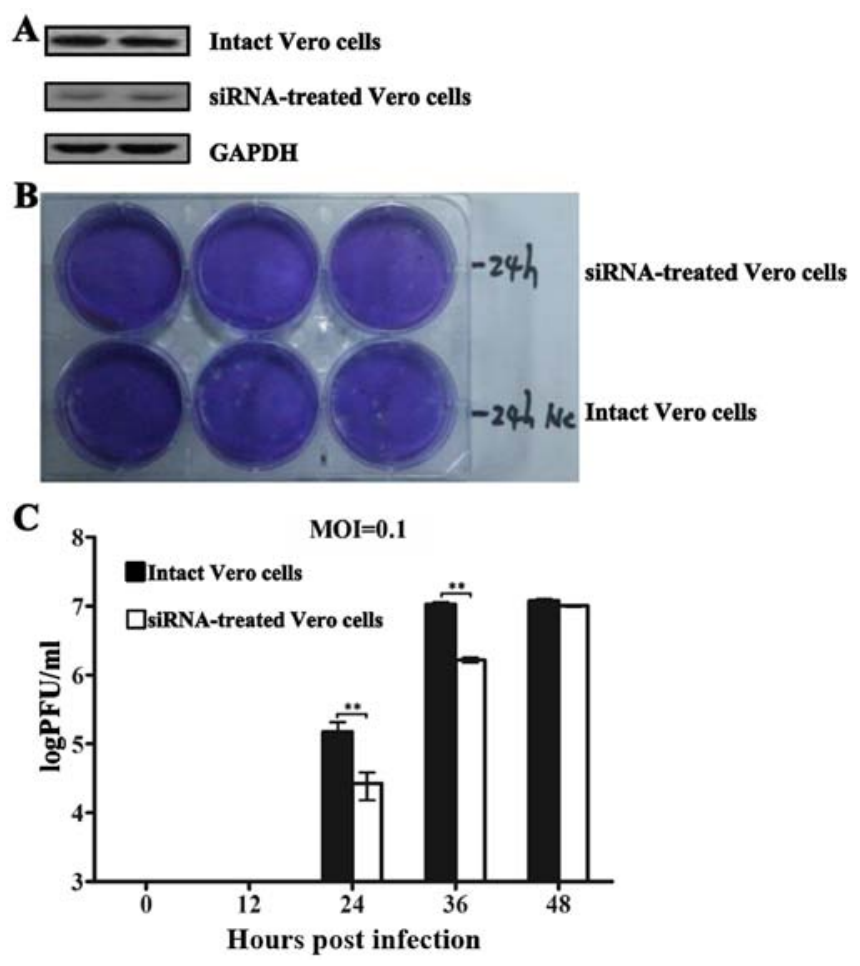

Figure 4. Decreased HSP90 $\beta$ expression in Vero cells reduces the JEV progeny yields. (A) The western blot analysis results revealed a decreased HSP90 $\beta$ expression in Vero cells transfected with an effective siRNA, in which GAPDH was monitored as the internal control. (B) Image of plaques formed in a 6-well plate in siRNA-treated and intact Vero cells at 24 hpi. (C) The JEV progeny yields were determined by plaque formation assay (PFU/ml) at 12 , 24,36 , and 48 hpi $(\mathrm{MOI}=0.1)$. ${ }^{* *} \mathrm{P}<0.01$. hpi, hours post-infection; GAPDH Glyceraldehyde-3-phosphate dehydrogenase; JEV, Japanese encephalitis virus.

Moreover, the percentages of HSP90 $\beta$-JEV binding measured by FCM also significantly decreased $(\mathrm{P}<0.01)$ from $76.17 \pm 0.69 \%(0 \mu \mathrm{g} / \mathrm{ml}$ anti-HSP90 $\beta \mathrm{mAb})$ to $19.15 \pm 0.35 \%(20 \mu \mathrm{g} / \mathrm{ml}$ anti-HSP90 $\beta \mathrm{mAb})$ and further to $10.43 \pm 0.53 \%(100 \mu \mathrm{g} / \mathrm{ml}$ anti-HSP90 $\beta \mathrm{mAb})$ compared with the negative controls of $1.70 \pm 0.11 \%$ (Fig. $3 \mathrm{~B}$ and $\mathrm{C}$ ). These results clearly demonstrated that a specific anti-HSP90 $\beta \mathrm{mAb}$ inhibited HSP90 $\beta$-JEV binding in a dose-dependent manner.

Decreased HSP90 $\beta$ expression in Vero cells reduces JEV progeny yields. siRNAs subcloned in lentivirus vectors were implemented to reduce HSP90 $\beta$ expression in Vero cells, and one transfected cell line exhibited an over $50 \%$ steady inhibition of HSP90 $\beta$ expression (Fig. 4A). Subsequent sequencing data revealed that the 21-nt siRNA (GGAUGACA GCGGUAAGGAUtt) was complementary to the human HSP90 $\beta$ mRNA 1012-1030 nt (GGATGACAGTGGTAA GGATAA), which is consistent with a previous report (31). Overall, the progeny virions in both intact and siRNA-treated Vero cell culture supernatants were detected at 24 (Fig. 4B), 36 and $48 \mathrm{hpi}$. The commensurate numbers of viral plaques at 36 and 48 hpi in the intact cells indicated that fewer infectious viruses were released, implicating that almost all cells became infected after $36 \mathrm{hpi}$ when the MOI was 0.1. However, in the siRNA-treated cells, the virion yields were significantly inhibited $(\mathrm{P}<0.01)$, particularly at 24 and $36 \mathrm{hpi}$, by 6.5 - and 5.6-fold, respectively (Fig. 4C).

\section{Discussion}

The conventional method for identifying virus receptors is a virus overlay protein-binding assay (VOPBA), where virions or virus attachment proteins (VAPs) are applied $(20,32)$. In a VOPBA, cell membrane protein extracts from virus-susceptible cells are first subjected to SDS-PAGE, transferred onto a nitrocellulose membrane, then incubated with virions or VAPs, and, finally, the specific virus-binding protein is indicated by specific enzyme-conjugated mAbs against the virus. However, VOPBA results cannot distinguish the virus-binding protein but only its size (molecular weight) $(33,34)$. For a successful VOPBA experiment, a single polypeptide must exhibit the tentative receptor activity, bind viruses without other membrane components and maintain binding activity in electrophoresis detergents (32). As it failed in a previous trial of VOPBA on BHK-21 cells in our laboratory, we used a Co-IP assay (35) instead to identify the JEV-binding protein with the advantage of a direct virus-membrane protein interaction under conditions that mimic physiological conditions and more natural conformations to enhance the certainty of protein binding. Due to the possible involvement of third party proteins unrelated to JEV binding in the immunoprecipitates, MS was necessarily introduced to probe the proteins in the precipitates and provide clues to the candidate JEV receptor (JEVR) protein(s) for further verification.

During the Co-IP experiments, unsurprisingly, more than one protein precipitated, and the most notable 3 bands (Fig. 1) compared with the controls were subjected to MS analyses. The MS results (Table I) suggested that novel proteins at approximately 95,43 and $34 \mathrm{kDa}$ are unnamed or hypothetical proteins (scores over 30) based on a monkey protein database (genus Macaca). Due to high genetic homogeneity between monkeys and humans, the human protein database (Homo sapiens) was quested, and the results revealed that the proteins were HSP90 $\beta$, an unnamed protein, the three-dimensional structure of glutathione s-transferase, and aconitase 2 precursor. Possessing the highest score of 60.3 among the four candidates, HSP90 $\beta$ is an entire, functional protein and was then selected for further investigation, though it is generally considered to be a cytoplasmic protein. Considering the inefficient separation of the hydrophobic and hydrophilic fractions during the cell membrane protein extraction procedures, it was not surprising to discover that a few hydrophilic proteins may be present in the hydrophobic fraction. However, the hydrophobic proteins remained dominant in this fraction. This finding is similar to our previous results when using BHK-21 membrane proteins (36).

HSPs are a class of chaperone proteins that assist other proteins in folding properly, stabilise proteins against heat stress, aid in protein degradation and stabilise many proteins required for tumour growth. They are the most highly conserved and expressed cellular proteins across all species (37). As their name implies, HSPs protect cells through increased expression from 1 to $2 \%$ of the total proteins in unstressed cells to $4-6 \%$ in stressed cells upon stimulation by elevated temperatures (38, and refs therein). HSP90 is one such heat-related chaperone protein and the '90' indicates that it weighs approximately $90 \mathrm{kDa}$. It is found in bacteria and all eukaryotes, but is absent in archaea (39), and its cytoplasmic counterpart is essential for cell viability under all conditions in eukaryotes (40). 
Mammalian cells feature several HSP90 isoform homologues (such as $\alpha 1, \alpha 2$ and $\beta$ ), which are defined by their different coding genes (HSP90AA1, HSP90AA2 and HSP90AB1), subcellular locations (cytosol, endoplasmic reticulum, and mitochondria) (41), or extracellular presence (42). Human HSP90 $\alpha$ is inducible, mostly forms anti-parallel homodimers, and is $85 \%$ identical to the HSP90 $\beta$ amino acid sequence, which is otherwise described as constitutive and a monomer due to several single amino acid mutations in the C-terminal dimerization domain (43-45).

No accurate HSP90 $\beta$ structure is available, even though it shares significant protein homology with its isoform HSP90 $\alpha$, which performs conservative functions in cells by forming homodimers. The crystal structures indicate that HSP90 $\alpha$ contains 3 functional domains: a highly conserved $\mathrm{N}$-terminal domain (NTD) of approximately $25 \mathrm{kDa}$, a middle domain (MD) of approximately $40 \mathrm{kDa}$ and a C-terminal domain (CTD) of approximately $12 \mathrm{kDa}$. The NTD exhibits a common ATP binding pocket that is shared among HSP90 chaperone family members and is recognised by its natural inhibitor, geldanamycin and its analogues $(46,47)$, which target the adenosine triphosphatase (ATPase activity) of the NTD region. The MD is involved in client protein binding involving, for example, PKB/Akt1 and eNOS $(48,49)$. The CTD features an alternative ATP-binding site that is only accessible when the N-terminal ATP-binding pocket is occupied (50). The CTD is also involved in protein binding because it includes the tetratricopeptide repeat (TPR) motif recognition site and conserved MEEVD pentapeptide that is responsible for co-factor interactions, including the immunophilins, stress-induced phosphoprotein 1 (Sti1/Hop), cyclophilin-40, PP5 and Tom70 (51-53).

Over the past few years, researchers have reported that several HSP family members (HSP90, HSP70, and HSC70) are putative receptors to certain flaviviruses $(23,24,26)$. Therefore, following the protein clues suggested by the MS analyses, we testified the specific binding of HSP90 $\beta$ in the Vero membrane protein extract and JEV particles.

Using western blot analysis, we only produced positive results under non-reducing and non-boiled conditions, which is in contrast to the routine reducing method (data not shown). The novel band at approximately $95 \mathrm{kDa}$ from the cell membrane protein extracts was reacted solely with either anti-human HSP90 $\beta \mathrm{mAb}$ recognizing the amino acid sequences 1-100 that correspond to the human HSP90 $\beta$ $\mathrm{N}$-terminus (see mAb manufacturer's fact sheet; http://www. abcam.com/hsp90-beta-antibody-e296-ab32568.html) or anti-JEV $\mathrm{mAb}$ against $\mathrm{E}$ protein at the same position around $90 \mathrm{kDa}$ (Fig. 2A). These data suggest that the HSP90 $\beta$-JEV complex formed as it was recognised by two different mAbs against the two respective complex components. In addition, the non-reducing and non-boiled conditions imply that the JEV binding activity of HSP90 $\beta$ may depend on the proper conformation of its monomers, which is sensitive to the detergents used in electrophoresis. This conformational requirement may partially explain why the VOPBA produced good results for the similar single peptide chain HSP70 $(24,54)$, but did not demonstrate why HSP90 $\beta$, which is broadly expressed in mouse brain cells (55), did not bind JEV on Neuro2A cells (24). For mouse microglial (BV-2) cells, HSP family members, including HSP70, HSP90 and GRP78, are also involved in JEV entry, but play a minor role in virus internalization, which is in contrast to CD4 with a major entry role (25). Furthermore, the confocal laser scanning microscopic examination demonstrated that HSP90 $\beta$ and JEV co-localised along the Vero cell surface (Fig. 2B), though HSP90 $\beta$ is generally defined as a cytosolic protein.

When HSP90 $\beta$-JEV binding was confirmed, an infection inhibition test was conducted using IFA and FCM with a rabbit anti-human HSP90 $\beta$ mAb at various concentrations. In the IFA experiment, the HSP90 $\beta$-JEV binding clearly decreased with the increasing anti-HSP90 $\beta \mathrm{mAb}$ concentrations, and the binding percentages quantified by FCM also exhibited a significant decrease $(\mathrm{P}<0.01)$ from $76.17 \pm 0.69 \%(0 \mu \mathrm{g} / \mathrm{ml}$ anti-HSP90 $\beta \mathrm{mAb})$ to $19.15 \pm 0.35 \%$ $(20 \mu \mathrm{g} / \mathrm{ml}$ anti-HSP90 $\beta \mathrm{mAb}$ ) and further to $10.43 \pm 0.53 \%$ $(100 \mu \mathrm{g} / \mathrm{ml}$ anti-HSP90 $\beta \mathrm{mAb})$ compared with the negative control of $1.70 \pm 0.11 \%$ (Fig. 3B). These results clearly demonstrate that the specific anti-HSP90 $\beta \mathrm{mAb}$ inhibited HSP90 $\beta$-JEV binding in a dose-dependent manner. Moreover, it is reasonable to presume that the JEV-binding domain of HSP90 $\beta$ is located at the $\mathrm{N}$-terminus, which is recognised by the anti-HSP $90 \beta \mathrm{mAb}$.

To elucidate the mechanisms through which HSP90 $\beta$ influences JEV infection in Vero cells, siRNA technology was used to knock down HSP90 $\beta$ expression instead of functional inhibitors, such as geldanamycin, which interferes with HSP90 $\beta$ ATPase activity (46). Several siRNA fragments directed to the human HSP90 $\beta$ mRNA sequence were synthesised and transfected into Vero cells via lentiviral vectors. We only selected out one transfected cell line with over 50\% steady inhibition of HSP90 $\beta$ expression (Fig. 4A), whose siRNA sequence is identical to an effective one reported earlier that corresponds to human HSP90 $\beta$ nt 1012-1030 (31). The plaque formation assay results indicated that cells with reduced HSP90 $\beta$ expression produced significantly less JEV progeny, particularly at 24 and 36 hpi (5.6-and 6.5-fold less, respectively).

Another report (56), stating that HSP90 $\beta$ is associated JEV assembly, but not during the adsorption phase, confirms that HSP90 $\beta$-JEV interaction at the attachment stage is the predominant factor for the decreased virus production.

In addition to interacting with JEV on the cell surface, HSP90 $\beta$ facilitates enterovirus 71 viral particle assembly in the human glioblastoma cell line SF268 (57). The different roles HSP90 $\beta$ plays during the different viral replication stages may be another intriguing field for investigation.

To summarise, we discovered that HSP90 $\beta$ in Vero cell membranes bound JEV on the cell surface, and the HSP90 $\beta$-JEV binding as well as virus progeny were inhibited by anti-human HSP90 $\beta \mathrm{mAb}$ and siRNA. This is in contrast to the aforementioned reports, which indicate that HSP70 family members are putative JEVR, HSP70 and its counterparts do not react to JEV in Vero cells. Furthermore, JEV seemed to prefer binding larger HSPs from HSC70 in mosquito cells to HSP90 in primate cells. In other words, these high molecular weight HSPs preserve the conservative conformation that distinctly fits JEV, and shifts from HSC70, HSP70 and then to HSP90 over millions years of evolution. To better support this presumption, more information pertaining JEV binding molecules on human susceptible cells is necessarily needed. 


\section{Acknowledgements}

The authors gratefully acknowledge financial support from the National Natural Scientific Foundation of China (no. 30872216 to T. D.). The funders did not play a role in the study design, data collection and analysis, the decision to publish, or the preparation of the manuscript. We would also thank the State Key Laboratory of Biomembrane and Membrane Biotechnology, Institute of Zoology, Chinese Academy of Sciences, Beijing for the MS analyses.

\section{References}

1. Daep CA, Muñoz-Jordán JL and Eugenin EA: Flaviviruses, an expanding threat in public health: Focus on dengue, West Nile, and Japanese encephalitis virus. J Neurovirol 20: 539-560, 2014

2. Misra UK and Kalita J: Overview: Japanese encephalitis. Prog Neurobiol 91: 108-120, 2010.

3. Yun SI and Lee YM: Japanese encephalitis: The virus and vaccines. Hum Vaccin Immunother 10: 263-279, 2014

4. Mackenzie JS, Johansen CA, Ritchie SA, van den Hurk AF and Hall RA: Japanese encephalitis as an emerging virus: the emergence and spread of Japanese encephalitis virus in Australasia. Curr Top Microbiol Immunol 267: 49-73, 2002.

5. Tsai TF: New initiatives for the control of Japanese encephalitis by vaccination: Minutes of a WHO/CVI meeting, Bangkok, Thailand, 13-15 October 1998. Vaccine 18: 1-25, 2000.

6. Solomon T and Vaughn DW: Pathogenesis and clinical features of Japanese encephalitis and West Nile virus infections. Curr Top microbiol Immunol 267: 171-194, 2002.

7. Solomon T and Winter PM: Neurovirulence and host factors in flavivirus encephalitis-evidence from clinical epidemiology. Arch Virol Suppl 18: 161-170, 2004.

8. Campbell GL, Hills SL, Fischer M, Jacobson JA, Hoke CH, Hombach JM, Marfin AA, Solomon T, Tsai TF, Tsu VD and Ginsburg AS.: Estimated global incidence of Japanese encephalitis: a systematic review. Bull World Health Organ 89: 766-774, 2011.

9. No authors listed: Japanese Encephalitis Vaccines: WHO position paper - February 2015. Wkly Epidemiol Rec 90: 69-87, 2015.

10. Ding D, Hong Z, Zhao SJ, Clemens JD, Zhou B, Wang B, Huang MS, Zeng J, Guo QH, Liu W, et al: Long-term disability from acute childhood Japanese encephalitis in Shanghai, China. Am J Trop Med Hyg 77: 528-533, 2007.

11. Sumiyoshi H, Mori C, Fuke I, Morita K, Kuhara S, Kondou J, Kikuchi Y, Nagamatu H and Igarashi A: Complete nucleotide sequence of the Japanese encephalitis virus genome RNA. Virology 161: 497-510, 1987.

12. Chambers TJ, Hahn CS, Galler R and Rice CM: Flavivirus genome organization, expression, and replication. Annu Rev Microbiol 44: 649-688, 1990

13. McMinn PC: The molecular basis of virulence of the encephalitogenic flaviviruses. J Gen Virol 78: 2711-2722, 1997.

14. Winkler G, Heinz FX and Kunz C: Studies on the glycosylation of flavivirus E proteins and the role of carbohydrate in antigenic structure. Virology 159: 237-243, 1987.

15. Luca VC, AbiMansour J, Nelson CA and Fremont DH: Crystal structure of the Japanese encephalitis virus envelope protein. $\mathrm{J}$ Virol 86: 2337-2346, 2012.

16. Rey FA, Heinz FX, Mandl C, Kunz C and Harrison SC: The envelope glycoprotein from tick-borne encephalitis virus at $2 \mathrm{~A}$ resolution. Nature 375: 291-298, 1995.

17. Allison SL, Schalich J, Stiasny K, Mandl CW and Heinz FX: Mutational evidence for an internal fusion peptide in flavivirus envelope protein E. J Virol 75: 4268-4275, 2001.

18. Kolaskar AS and Kulkarni-Kale U: Prediction of three-dimensional structure and mapping of conformational epitopes of envelope glycoprotein of Japanese encephalitis virus. Virology 261: 31-42, 1999.

19. Wu KP, Wu CW, Tsao YP, Kuo TW, Lou YC, Lin CW, Wu SC and Cheng JW: Structural basis of a flavivirus recognized by its neutralizing antibody: Solution structure of the domain III of the Japanese encephalitis virus envelope protein. J Biol Chem 278: 46007-46013, 2003.

20. Kimura T, Kimura-Kuroda J, Nagashima K and Yasui K: Analysis of virus-cell binding characteristics on the determination of Japanese encephalitis virus susceptibility. Arch Virol 139: 239-251, 1994.
21. Su CM, Liao CL, Lee YL and Lin YL: Highly sulfated forms of heparin sulfate are involved in japanese encephalitis virus infection. Virology 286: 206-215, 2001.

22. Wu SC, Chiang JR and Lin CW: Novel cell adhesive glycosaminoglycan-binding proteins of Japanese encephalitis virus. Biomacromolecules 5: 2160-2164, 2004.

23. Ren Junping LY, Wei Z, Jing Y and Ma W. Chin. Isolation and preliminary identification of $74 \times 103$ molecule as putative Japanese encephalitis virus receptor. J Microbiol Immunol 29: 307-311, 2009.

24. Das S, Laxminarayana SV, Chandra N, Ravi V and Desai A Heat shock protein 70 on Neuro2a cells is a putative receptor for Japanese encephalitis virus. Virology 385: 47-57, 2009.

25. Thongtan T, Wikan N, Wintachai P, Rattanarungsan C, Srisomsap C, Cheepsunthorn P and Smith DR: Characterization of putative Japanese encephalitis virus receptor molecules on microglial cells. J Med Virol 84: 615-623, 2012.

26. Chu JJ, Leong PW and Ng ML: Characterization of plasma membrane-associated proteins from Aedes albopictus mosquito (C6/36) cells that mediate West Nile virus binding and infection. Virology 339: 249-260, 2005.

27. Zhang MJ, Wang MX, Jiang SZ, Xiu ZZ and Ma WY: Preparation and characterization of the monoclonal antibodies against Japanese encephalitis virus. Acta Virol 36: 533-540, 1992.

28. Perkins DN, Pappin DJ, Creasy DM and Cottrell JS: Probability-based protein identification by searching sequence databases using mass spectrometry data. Electrophoresis 20: 3551-3567, 1999

29. Everett RD: Study of early events during herpes simplex virus type 1 infection by confocal microscopy. Methods 55: 144-152, 2011.

30. Henschel A, Buchholz F and Habermann B: DEQOR: A web-based tool for the design and quality control of siRNAs. Nucleic Acids Res 32 (Web Server): W113-20, 2004.

31. Schulz R, Marchenko ND, Holembowski L, Fingerle-Rowson G, Pesic M, Zender L, Dobbelstein M and Moll UM: Inhibiting the HSP90 chaperone destabilizes macrophage migration inhibitory factor and thereby inhibits breast tumor progression. J Exp Med 209: 275-289, 2012.

32. Haywood AM: Virus receptors: Binding, adhesion strengthening, and changes in viral structure. J Virol 68: 1-5, 1994.

33. Salas-Benito JS and del Angel RM: Identification of two surface proteins from $\mathrm{C} 6 / 36$ cells that bind dengue type 4 virus. J Virol 71: 7246-7252, 1997.

34. Martínez-Barragán JJ and del Angel RM: Identification of a putative coreceptor on Vero cells that participates in dengue 4 virus infection. J Virol 75: 7818-7827, 2001

35. Li W, Moore MJ, Vasilieva N, Sui J, Wong SK, Berne MA, Somasundaran M, Sullivan JL, Luzuriaga K, Greenough TC, et al: Angiotensin-converting enzyme 2 is a functional receptor for the SARS coronavirus. Nature 426: 450-454, 2003.

36. Ding T, Zhang W, Ma W and Ren J: Identification of a mutated BHK-21 cell line that became less susceptible to Japanese encephalitis virus infection. Virol J 8: 115, 2011.

37. Csermely P, Schnaider T, Soti C, Prohászka Z and Nardai G: The 90-kDa molecular chaperone family: Structure, function, and clinical applications. A comprehensive review. Pharmacol Ther 79: 129-168, 1998.

38. Crevel G, Bates H, Huikeshoven H and Cotterill S: The Drosophila Dpit47 protein is a nuclear Hsp90 co-chaperone that interacts with DNA polymerase alpha. J Cell Sci 114: 2015-2025, 2001.

39. Chen B, Zhong D and Monteiro A: Comparative genomics and evolution of the HSP90 family of genes across all kingdoms of organisms. BMC Genomics 7: 156, 2006.

40. Thomas JG and Baneyx F: Roles of the Escherichia coli small heat shock proteins IbpA and IbpB in thermal stress management: Comparison with ClpA, ClpB, and HtpG In vivo. J Bacteriol 180: 5165-5172, 1998.

41. Chen B, Piel WH, Gui L, Bruford E and Monteiro A: The HSP90 family of genes in the human genome: Insights into their divergence and evolution. Genomics 86: 627-637, 2005.

42. Correia AL, Mori H, Chen EI, Schmitt FC and Bissell MJ: The hemopexin domain of MMP3 is responsible for mammary epithelial invasion and morphogenesis through extracellular interaction with HSP90 $\beta$. Genes Dev 27: 805-817, 2013.

43. Nemoto T, Ohara-Nemoto Y, Ota M, Takagi T and Yokoyama K: Mechanism of dimer formation of the $90-\mathrm{kDa}$ heat-shock protein. Eur J Biochem 233: 1-8, 1995.

44. Barginear MF, Van Poznak C, Rosen N, Modi S, Hudis CA and Budman DR: The heat shock protein 90 chaperone complex: An evolving therapeutic target. Curr Cancer Drug Targets 8: $522-532,2008$. 
45. Kobayakawa T, Yamada S, Mizuno A and Nemoto TK: Substitution of only two residues of human Hsp90alpha causes impeded dimerization of Hsp90beta. Cell Stress Chaperones 13: 97-104, 2008.

46. Ochel HJ, Eichhorn K and Gademann G: Geldanamycin: the prototype of a class of antitumor drugs targeting the heat shock protein 90 family of molecular chaperones. Cell Stress Chaperones 6: 105-112, 2001.

47. Kamal A, Thao L, Sensintaffar J, Zhang L, Boehm MF, Fritz LC and Burrows FJ: A high-affinity conformation of Hsp90 confers tumour selectivity on Hsp90 inhibitors. Nature 425: 407-410, 2003.

48. Sato S, Fujita N and Tsuruo T: Modulation of Akt kinase activity by binding to Hsp90. Proc Natl Acad Sci USA 97: 10832-10837, 2000.

49. Fontana J, Fulton D, Chen Y, Fairchild TA, McCabe TJ, Fujita N, Tsuruo T and Sessa WC: Domain mapping studies reveal that the $\mathrm{M}$ domain of hsp90 serves as a molecular scaffold to regulate Akt-dependent phosphorylation of endothelial nitric oxide synthase and NO release. Circ Res 90: 866-873, 2002.

50. Söti C, Rácz A and Csermely P: A Nucleotide-dependent molecular switch controls ATP binding at the C-terminal domain of Hsp90. N-terminal nucleotide binding unmasks a C-terminal binding pocket. J Biol Chem 277: 7066-7075, 2002.
51. Young JC, Obermann WM and Hartl FU: Specific binding of tetratricopeptide repeat proteins to the C-terminal $12-\mathrm{kDa}$ domain of hsp90. J Biol Chem 273: 18007-18010, 1998.

52. Pearl LH and Prodromou C: Structure, function, and mechanism of the Hsp90 molecular chaperone. Adv Protein Chem 59: 157-186, 2001.

53. Wandinger SK, Richter K and Buchner J: The Hsp90 chaperone machinery. J Biol Chem 283: 18473-18477, 2008

54. Daugaard $M$, Rohde $M$ and Jäättelä $M$ : The heat shock protein 70 family: Highly homologous proteins with overlapping and distinct functions. FEBS Lett 581: 3702-3710, 2007.

55. Loones MT, Chang Y and Morange M: The distribution of heat shock proteins in the nervous system of the unstressed mouse embryo suggests a role in neuronal and non-neuronal differentiation. Cell Stress Chaperones 5: 291-305, 2000.

56. Hung CY, Tsai MC, Wu YP and Wang RY: Identification of heat-shock protein 90 beta in Japanese encephalitis virus-induced secretion proteins. J Gen Virol 92: 2803-2809, 2011.

57. Wang RY, Kuo RL, Ma WC, Huang HI, Yu JS, Yen SM, Huang CR and Shih SR: Heat shock protein-90-beta facilitates enterovirus 71 viral particles assembly. Virology 443: 236-247, 2013. 